\title{
Quantitative Susceptibility Mapping and R2* Measured Changes during White Matter Lesion Development in Multiple Sclerosis: Myelin Breakdown, Myelin Debris Degradation and Removal, and Iron Accumulation
}

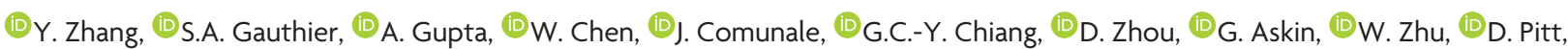
and $(1)$ Y. Wang

trom

\begin{abstract}
BACKGROUND AND PURPOSE: Quantitative susceptibility mapping and R2* are sensitive to myelin and iron changes in multiple sclerosis lesions. This study was designed to characterize lesion changes on quantitative susceptibility mapping and R2* at various gadoliniumenhancement stages.
\end{abstract}

MATERIALS AND METHODS: This study included 64 patients with MS with different enhancing patterns in white matter lesions: nodular, shell-like, nonenhancing $<1$ year old, and nonenhancing $1-3$ years old. These represent acute, late acute, early chronic, and late chronic lesions, respectively. Susceptibility values measured on quantitative susceptibility mapping and R2* values were compared among the 4 lesion types. Their differences were assessed with a generalized estimating equation, controlling for Expanded Disability Status Scale score, age, and disease duration.

RESULTS: We analyzed 203 lesions: 80 were nodular-enhancing, of which 77 (96.2\%) were isointense on quantitative susceptibility mapping; 33 were shell-enhancing, of which 30 (90.9\%) were hyperintense on quantitative susceptibility mapping; and 49 were nonenhancing lesions $<1$ year old and 41 were nonenhancing lesions $1-3$ years old, all of which were hyperintense on quantitative susceptibility mapping. Their relative susceptibility/R2* values were $0.5 \pm 4.4$ parts per billion/ $-5.6 \pm 2.9 \mathrm{~Hz}, 10.2 \pm 5.4$ parts per billion/ $-8.0 \pm 2.6 \mathrm{~Hz}$, $20.2 \pm 7.8$ parts per billion/ $-3.1 \pm 2.3 \mathrm{~Hz}$, and $33.2 \pm 8.2$ parts per billion/ $-2.0 \pm 2.6 \mathrm{~Hz}$, respectively, and were significantly different $(P<$ .005).

CONCLUSIONS: Early active MS lesions with nodular enhancement show R2* decrease but no quantitative susceptibility mapping change, reflecting myelin breakdown; late active lesions with peripheral enhancement show R2* decrease and quantitative susceptibility mapping increase in the lesion center, reflecting further degradation and removal of myelin debris; and early or late chronic nonenhancing lesions show both quantitative susceptibility mapping and $\mathrm{R} 2 *$ increase, reflecting iron accumulation.

ABBREVIATIONS: Gd = gadolinium; GRE = gradient-echo; $Q S M=$ quantitative susceptibility mapping

The he pathologic changes in active white matter MS lesions include inflammatory infiltration with immune cells, myelin breakdown and removal by microglia/macrophages, and iron accumulation in immune cells within the lesion and the lesion periphery. ${ }^{1,2}$

Received October 5, 2015; accepted after revision February 18, 2016.

From the Department of Radiology (Y.Z., W.C., W.Z.), Tongji Hospital, Tongji Medical College, Huazhong University of Science and Technology, Wuhan, China; Departments of Radiology (Y.Z., A.G., J.C., G.C.-Y.C., D.Z., Y.W.), Neurology (S.A.G.) and Healthcare Policy and Research (G.A.), Weill Cornell Medical College, New York, New York; Department of Neurology (D.P.), School of Medicine, Yale University, New Haven, Connecticut; and Department of Biomedical Engineering (Y.W.), Cornell University, Ithaca, New York.

Authors' contributions: Acquisition of data, analysis and interpretation of data, writing (Y.Z.); conception and design, acquisition of data, clinical study, manuscript revision (S.A.G.); acquisition of data, interpretation of image data, manuscript revision (A.G., W.C., J.C., G.C.-Y.C.); conception and design, manuscript revision (D.Z.); statistical analysis of data, statistical analysis writing (G.A.); conception and design, manuscript revision, study supervision (W.Z.); study conception, manuscript revision (D.P.); study conception and design, critical revision of manuscript, study supervision (Y.W.).
MR imaging staging of white-matter MS lesions uses gadolinium $(\mathrm{Gd})$ enhancement to differentiate between active (enhancing) and nonactive (nonenhancing) lesions. However, enhancement provides only a short window into inflammatory activity

All authors had the "final approval of the version to be published" and "agreement to be accountable for all aspects of the work in ensuring that questions related to the accuracy or integrity of any part of the work are appropriately investigated and resolved."

This work was supported by grant NS090464 from the U.S. Department of Health and Human Services-National Institutes of Health-National Institute of Neurological Disorders and Stroke, grant EB134432 from the U.S. Department of Health and Human Services-National Institutes of Health-National Institute of Biomedical Imaging and Bioengineering, and grant 81401390 from the National Natural Science Foundation of China.

Please address correspondence to Yi Wang, PhD, Department of Radiology, Weill Cornell Medical College, 515 East 71th St, New York, NY 10021; e-mail: yiwang@med.cornell.edu

- Indicates open access to non-subscribers at www.ajnr.org

http://dx.doi.org/10.3174/ajnr.A4825 


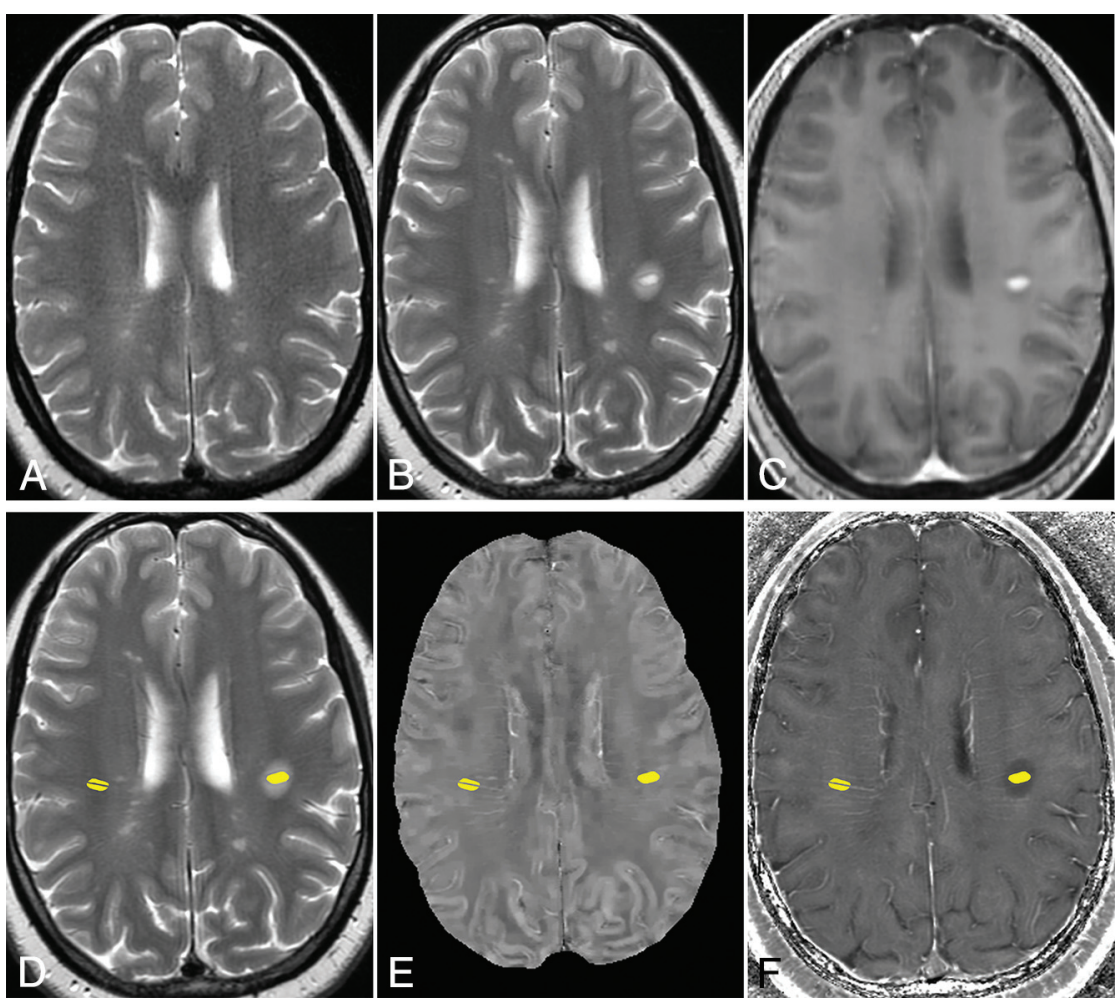

FIG 1. Example of ROls of an MS lesion and reference at normal-appearing WM in a 44-year-old woman with MS. A, T2WI 8 months before the appearance of the enhancing lesion. $B, T 2 \mathrm{WI}$, and $C, \mathrm{TTWI}+\mathrm{Gd}$ image of 1 enhancing MS lesion. $D, \mathrm{~T} 2 \mathrm{WI}, E, \mathrm{QSM}$, and $F, \mathrm{R}^{*}$ images with ROls of the enhancing lesion (left side) and the normal-appearing WM (right side). The vein inside the selected normal-appearing WM is excluded.

because it is preceded and outlasted by infiltration with immune cells. Enhancement on T1WI + Gd reflects BBB damage, whereas conventional MR imaging (T2WI and T1WI) sensitizing water mobility does not reflect specific microstructural and compositional changes in active lesions. ${ }^{3}$ In contrast, gradient-echo (GRE) imaging is sensitive to the magnetic fields induced by inhomogeneous myelin and highly paramagnetic iron, offering the potential to study microstructural and compositional changes in active MS lesions. ${ }^{4-11}$ GRE imaging data can be processed to generate quantitative susceptibility mapping (QSM) $)^{12,13}$ and R2* maps. QSM measures the underlying total magnetic susceptibility sources in a voxel. ${ }^{7,12} \mathrm{R} 2{ }^{*}$ reflects the sum of the $\mathrm{T} 2$ relaxation rate that depends on cellular content ${ }^{14}$ and the field dispersion associated with susceptibility microstructural heterogeneity multiplied by TE. ${ }^{6,12}$ Breakdown of intact myelin decreases $\mathrm{R} 2{ }^{*}$ but does not change QSM signal, whereas degradation of diamagnetic myelin debris within macrophages and removal of degraded myelin increase susceptibility measured on QSM. Finally, iron accumulation increases both R2* and QSM. ${ }^{6,7,9,15,16}$ Therefore, by using both QSM and R2*, we would be able to differentiate between acute myelin breakdown, advanced myelin degradation and removal, and iron accumulation in MS lesions.

\section{MATERIALS AND METHODS \\ Patients}

The Weill Cornell Medical College institutional review board approved this MR imaging study of patients with MS from August 2011 to April 2015. The inclusion criteria were patients who 1) had undergone, within 12 months, 2 successive MRIs that included T2WI, and pre- and post-Gd T1WI, with the second MR imaging including a multiecho GRE imaging; and 2) had new hyperintense white matter lesions on the second T2WI. A total of 65 patients met the inclusion criteria; 1 patient was excluded a posteriori because of motion artifacts on GRE images. The mean age of the 64 patients (13 men and 51 women) was $35.29 \pm 8.12$ years, with age ranging from 11-51 years. Patients were receiving the steroid SoluMedrol intravenous injection (3 mg/ day for 3 to 5 days). All their disease durations ranged from $0-17$ years $(6.0 \pm 4.71$ years $)$ and the Expanded Disability Status Scale scores ranged from 0-6 (median, 1.5; interquartile range, 3 ).

\section{Imaging Protocol and Reconstruction}

MR imaging was performed on a 3T MR scanner (Signa HDxt; GE Healthcare, Milwaukee, Wisconsin) with an 8-channel head coil. The sequences for each patient were: 1) T2-weighted FSE (TR/ $\mathrm{TE}=5250 / 86 \mathrm{msec}$, flip angle $=90^{\circ}$, 3 -mm-thick section at 0 intervals, $416 \times 256$ matrix, $24-\mathrm{cm}$ FOV); 2) pre- and 3) post-Gd 3D inversion recovery-prepared T1-weighted fast echo-spoiled gradient-echo $(\mathrm{TR} / \mathrm{TE}=8.8 / 3.4$ msec, flip angle $=15^{\circ}, 256 \times 256$ matrix, 24-cm FOV, $0.45 \times$ $0.45 \times 1.2 \mathrm{~mm}^{3}$ resolution); and 4) $3 \mathrm{D} \mathrm{T} 2^{\star}$-weighted spoiled multiecho GRE sequence. Imaging parameters for the multiecho GRE sequence were as follows: TR $=57 \mathrm{msec}$; number of echoes $=11$; first $\mathrm{TE}=4.3 \mathrm{msec}$; $\mathrm{TE}$ spacing $=4.8 \mathrm{msec}$; flip angle $=20^{\circ}$; bandwidth $=244 \mathrm{kHz} ; \mathrm{FOV}=24 \mathrm{~cm}$; thickness $=2$ $\mathrm{mm}$; acquisition matrix $=416 \times 320$; acquisition voxel size $=$ $0.5 \times 0.5 \times 2 \mathrm{~mm}^{3}$. The GRE sequence was performed before Gd injection, and the post-Gd T1WI was performed at 4 minutes after Gd injection.

QSM was reconstructed from the data acquired with the GRE sequence by using the morphology-enabled dipole inversion ${ }^{17}$ method, and R2* maps were generated by using a Gauss-Newton least-squares mono-exponential fit of the 11 echoes. ${ }^{18}$ QSM and $\mathrm{R} 2{ }^{*}$ were reconstructed to a matrix of $512 \times 512$, resulting in a voxel size of $0.47 \times 0.47 \times 2 \mathrm{~mm}^{3}$. All images of 1 patient were registered to the QSM image by using the FMRIB Linear Image Registration Tool (FLIRT; http://www.fmrib.ox.ac.uk/). ${ }^{19}$

\section{Lesion Analysis}

New white matter MS lesions were identified on the second MR imaging, which was performed at $0.77 \pm 0.37$ year after the first MR imaging. Three neuroradiologists (J.C., A.G., and G.C.-Y.C., with 18,9 , and 8 years of experience, respectively) independently 


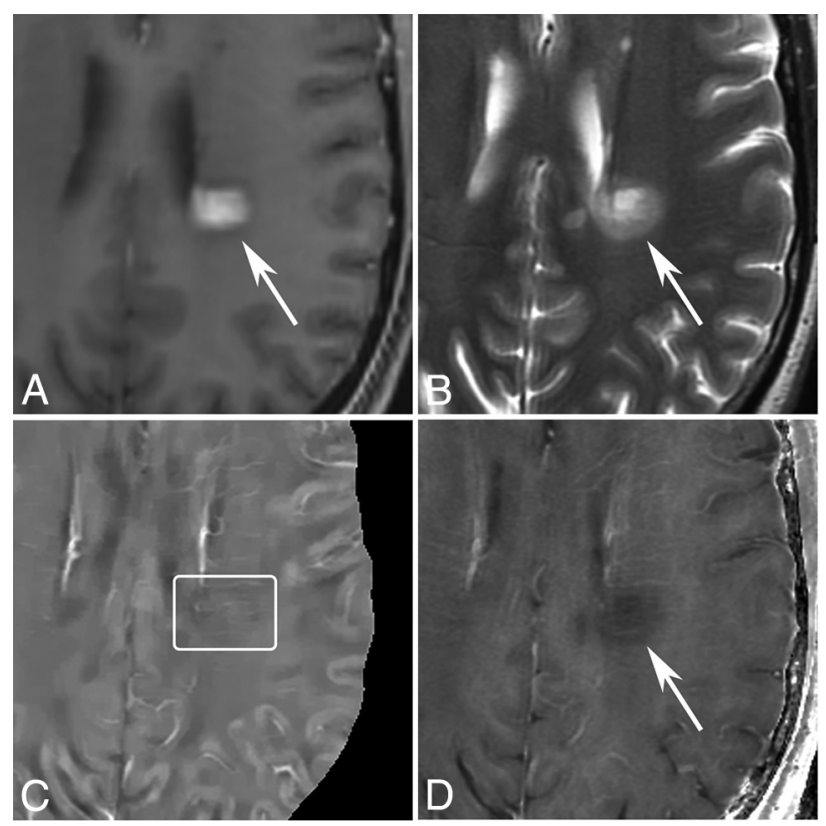

FIG 2. MR images of a nodular-enhancing lesion in a 43-year-old man with MS. A, TIWI + Gd. B, T2WI. C, QSM.D, R2*. A nodular-enhancing lesion (arrows) is found on the TTWI + Gd and appears QSM isointense ( $C$, box).

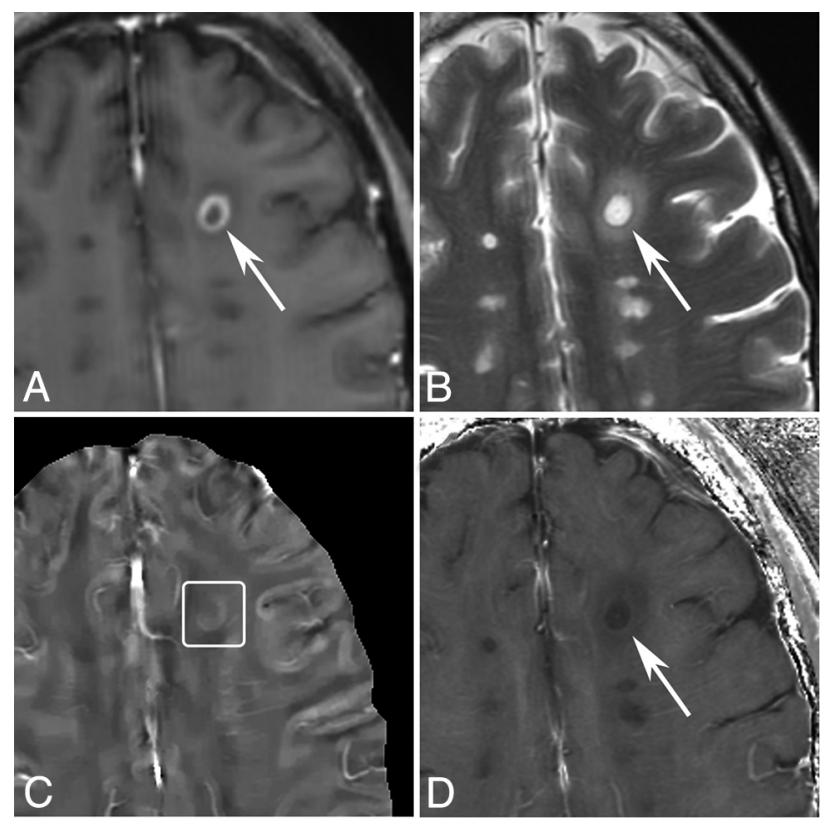

FIG 3. MR images of a shell-enhancing lesion in a 51-year-old man with MS. A, TIWI + Gd. B, T2WI. C, QSM. D, R2*. A shell-enhancing lesion (arrows) is found on the TIWI + Gd and appears slightly QSM hyperintense $(C, b o x)$.

reviewed all images of the selected patients and classified new lesions into 3 groups based on enhancement on T1WI + Gd (nodular-enhancing [solid in 2D], shell-enhancing [ringlike in $2 \mathrm{D}],{ }^{20}$ and nonenhancing $<1$ year old). By comparison to an MR imaging $<3$ years old, lesions $1-3$ years old $(1.57 \pm 0.46$ years; error, $0.88 \pm 0.34$ years) from the same cohort were identified as a fourth group. The method of estimating lesion age referred to a previous study. ${ }^{7}$ All these lesions were independently assessed by the 3 neuroradiologists to be hyperintense or isointense on QSM
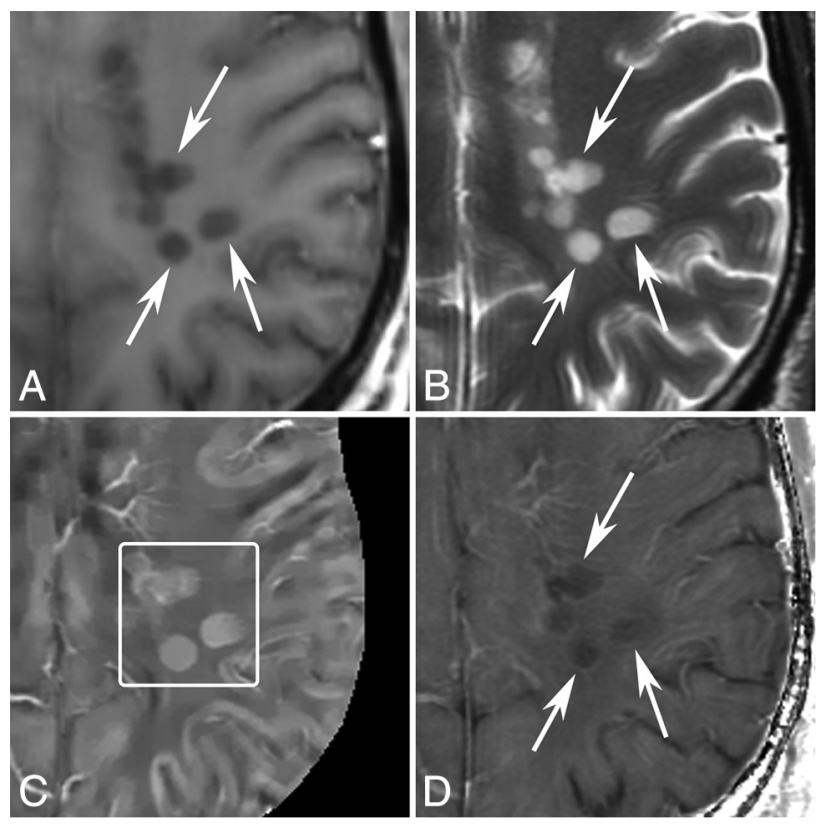

FIG 4. MR images of new $T 2$ nonenhancing lesions ( $<0.7$ years old) in a 42-year-old man with MS. A, TIWI + Gd. B, T2WI. C, QSM. D, R2*. More than 3 new nonenhancing lesions (arrows) are found by comparing with the former MR imaging 0.7 years ago. All of them appear QSM hyperintense $(C$, box $)$ and have hyperintense rims on $\mathrm{R}^{*}$.

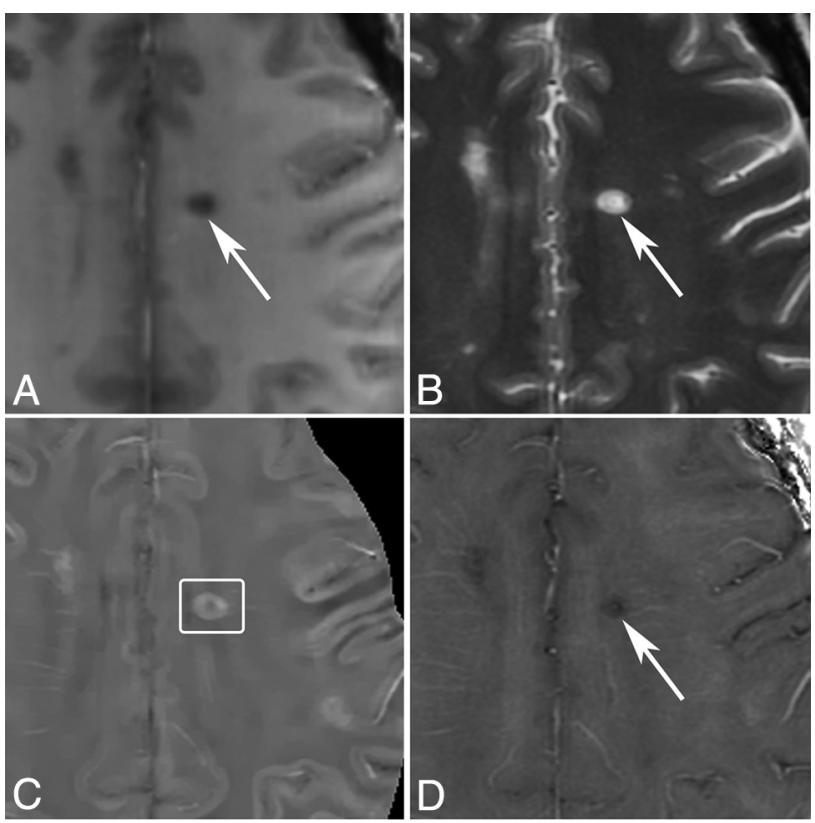

FIG 5. MR images of a nonenhancing lesion that is 1.2 years old in a 48-year-old woman with MS. A, TTWI + Gd. B, T2WI. C, QSM. D, R2*. One lesion appears hyperintense with a thick rim on QSM and hypointense on $\mathrm{R} 2 *$.

images. These 3 readings were combined, with all differences resolved by majority votes.

ROIs of the lesions were placed on the lesion's hyperintense area on T2-weighted images, but the edema around was not included. If a lesion had a hypointense rim on T2WI, we also excluded this rim (example is shown on Fig 1). ROIs as normalappearing white matter references were drawn on the contralateral mirror site of the lesions with similar shape and size. 
One neuroradiologist (Y.Z., 4 years of experience) drew the ROIs on T2WI and then overlaid them on QSM and R2* maps by using in-house ROI semiautomatic software implemented for OsiriX (http://www.osirix-viewer.com). The veins and artifacts inside lesions on QSM and R2* were carefully removed by hand.

\section{Statistical Analysis}

The differences in relative susceptibilities and $\mathrm{R} 2{ }^{*}$ values of lesions in the 4 groups were assessed by a generalized estimating equation. This model assumes a Gaussian distribution and an exchangeable correlation structure to account for the multiple
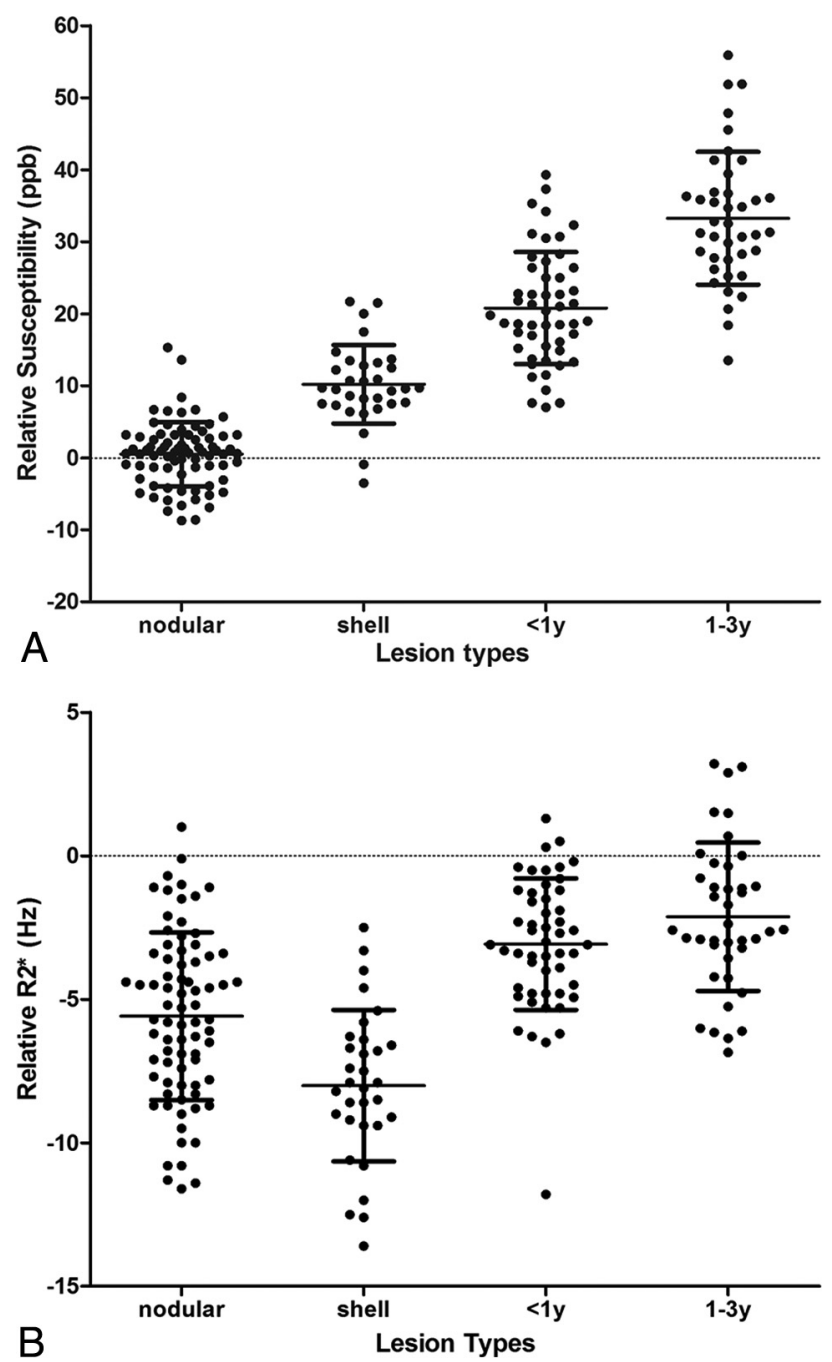

FIG 6. Scatterplot of susceptibility relative to normal-appearing WM measured on $A, \mathrm{QSM}$ and $B, \mathrm{R} 2^{*}$. ppb indicates parts per billion.

Table 1: Quantitative susceptibility and R2* values for nodular-enhancing, shell-enhancing, nonenhancing $<1$ year, and nonenhancing $1-3$ years old lesions

\begin{tabular}{lcccc}
\hline & Nodular & Shell & $\begin{array}{c}\text { Nonenhancing } \\
<1 \text { Year }\end{array}$ & $\begin{array}{c}\text { Nonenhancing } \\
\text { 1-3 Years }\end{array}$ \\
\hline No. of lesions & 77 & 32 & 48 & 41 \\
No. of patients & 32 & 21 & 27 & 20 \\
$\begin{array}{l}\text { Susceptibility relative } \\
\text { to NAWM, ppb }\end{array}$ & $0.5 \pm 4.4$ & $10.2 \pm 5.4$ & $20.2 \pm 7.8$ & $33.2 \pm 8.2$ \\
R2* values relative to & $-5.6 \pm 2.9$ & $-8.0 \pm 2.6$ & $-3.1 \pm 2.3$ & $-2.0 \pm 2.6$ \\
NAWM, Hz & & & & \\
\hline
\end{tabular}

Note:-NAWM indicates normal-appearing white matter; ppb, parts per billion.

1632 Zhang Sep 2016 www.ajnr.org
QSM and R2* measurements per patient. A multivariable model was used to assess the independent effect of enhancing patterns on QSM and R2*, controlling for Expanded Disability Status Scale score, age, and disease duration. Age, Expanded Disability Status Scale score, and disease duration were assessed for the presence of collinearity. All analyses were performed in SAS Version 9.4 (SAS Institute, Cary, North Carolina). $P<.05$ was considered statistically significant.

\section{RESULTS}

\section{Lesion Pattern Characteristics}

A total of 205 white matter lesions (115 enhancing and 90 nonenhancing) were examined in the 64 patients. Two enhancing lesions were excluded because they were too close to the cranium and did not appear intact on QSM. The 203 white matter lesions analyzed consisted of 80 (39.4\%) new nodular-enhancing lesions, $33(16.3 \%)$ shell-enhancing lesions, $49(24.1 \%)$ new nonenhancing lesions $<1$ year old, and 41 (20.2\%) nonenhancing lesions 1-3 years old. Of the 80 new nodular-enhancing lesions, 77 (96.2\%) appeared isointense on QSM and 3 (3.8\%) lesions were hyperintense on QSM. Of the 33 new shell-enhancing lesions, 30 (90.9\%) appeared hyperintense on QSM and 3 (9.1\%) lesions were isointense on QSM. All nonenhancing lesions (49 [100\%] with age $<1$ year and 41 [100\%] with age 1-3 years old) were hyperintense on QSM. Example images are shown in Figs 2-5.

\section{Lesion Susceptibility and R2* Value Analyses}

The reference areas on the contralateral site of 5 new lesions ( 3 nodular-enhancing, 1 shell-enhancing, and 1 nonenhancing) were covered by MS lesions, which prevented us from assessing reference values for susceptibilities and $\mathrm{R} 2{ }^{*}$. The relative susceptibilities and $\mathrm{R} 2^{*}$ values were measured and calculated in 198 lesions (77 nodular-enhancing, 32 shell-enhancing, 48 nonenhancing with age $<1$ year, and 41 nonenhancing with age $1-3$ years).

Quantitative susceptibilities and R2* values are plotted in Fig 6 and are summarized in Table 1. Nodular-enhancing lesions had relative susceptibilities near zero $(0.5 \pm 4.4$ parts per billion $)$, shell-enhancing lesions had increased relative susceptibilities $(10.2 \pm 5.4$ parts per billion), nonenhancing lesions $<1$ year old had higher relative susceptibilities (20.2 \pm 7.8 parts per billion), and nonenhancing lesions $1-3$ years old had the highest relative susceptibility $(33.2 \pm 8.2$ parts per billion). In the generalized estimating equation model, after controlling for Expanded Disability Status Scale score, age, and disease duration, there were significant differences between each 2 types of lesions $(P<.0001)$. The nodular-enhancing, shell-enhancing, and new nonenhancing lesion types ( $<1$ year) had lower relative susceptibilities compared with the more stable lesions (1-3 years). These relationships were significant at all levels $(P<.0001) . \mathrm{R} 2^{*}$ values relative to normal-appearing $\mathrm{WM}$ were $-5.6 \pm 2.9$ $\mathrm{Hz},-8.0 \pm 2.6 \mathrm{~Hz},-3.1 \pm 2.3 \mathrm{~Hz}$, and $-2.0 \pm 2.6 \mathrm{~Hz}$ of nodular-enhancing, shell-enhancing, nonenhancing $<1$ year old, and nonenhancing 1-3 years old lesions, respectively. These relation- 
Table 2: Statistical comparison of relative susceptibility from 4 groups of lesions ${ }^{\mathrm{a}}$

\begin{tabular}{lccc}
\hline Comparison & Nodular & Shell & $<1$ year \\
\hline Shell & $-9.8621,(-11.7759,-7.9484), P<.0001$ & - & - \\
$<1$ year & $-20.3123,(-23.0288,-17.5959), P<.0001$ & $-10.4502,(-13.6101,-7.2903), P<.0001$ & - \\
$1-3$ years & $-32.6287,(-35.9416,-29.3159), P<.0001$ & $-22.7666,(-26.2751,-19.2581), P<.0001$ & $-12.3164,(-16.3345,-8.2983), P<.0001$ \\
\hline
\end{tabular}

${ }^{a}$ Data given as relative parameter estimates $(\beta)$, (95\% confidence limits), $P$ value. Parameter estimates, $95 \% \mathrm{Cl}$, and $\mathrm{SE}$ from multivariable generalized estimating equation, controlling for age, Expanded Disability Status Scale score, and disease duration. $\beta$ estimates were obtained by setting the reference category to different lesion group.

Table 3: Statistical comparison of relative R2* from 4 groups of lesions ${ }^{\mathrm{a}}$

\begin{tabular}{lccc}
\hline Comparison & Nodular & Shell & $<1$ year \\
\hline Shell & $2.3409,(1.4980,3.1837), P<.0001$ & - & - \\
$<1$ year & $-2.4309,(-3.1174,-1.7443), P<.0001$ & $-4.7717,(-5.7643,-3.7792), P<.0001$ & - \\
$1-3$ years & $-3.6385,(-4.6191,-2.6578), P<.0001$ & $-5.9793,(-7.0956,-4.863),. P<.0001$ & $-1.2076,(-2.0439,-0.3712), P=.0047$ \\
\hline
\end{tabular}

${ }^{a}$ Data given as relative parameter estimates $(\beta)$, (95\% confidence limits), $P$ value. Parameter estimates, $95 \% \mathrm{Cl}$, and SE from multivariable generalized estimating equation, controlling for age, Expanded Disability Status Scale, and disease duration. $\beta$ estimates were obtained by setting the reference category to different lesion group.

ships were maintained in the generalized estimating equation model after controlling for the relevant clinical characteristics of age, Expanded Disability Status Scale score, and disease duration. Lesion types of nodular-enhancing, shell-enhancing, and new nonenhancing lesions $<1$ year old were associated with lower $\mathrm{R} 2{ }^{*}$ values compared with stable lesions (1-3 years), with shell-enhancing lesions having the largest relative decrease. All associations were significant at the $P<.01$ level. The results of statistical analysis are shown in Tables 2 and 3.

\section{DISCUSSION}

Our results demonstrate the following QSM and R2* patterns for MS lesions: nodular-enhancing lesions on T1WI + Gd that are isointense on QSM and hypointense on R2*; susceptibility increases and $\mathrm{R} 2^{\star}$ decreases as lesions develop from nodular- to ring-enhancing; and increase in susceptibility and $\mathrm{R} 2{ }^{*}$ in lesions that become nonenhancing. According to the imaging physics ${ }^{12}$ and the known pathophysiology of MS white matter lesions, ${ }^{2}$ these observed QSM and R2* patterns can be interpreted as sequential pathologic changes in myelin and iron content ${ }^{2}$ that occur during the early stages of lesion development. Our results suggest that GRE data provide valuable information about MS lesion pathology beyond conventional MR imaging sequences.

We used T1WI + Gd to characterize the temporal sequence of MS lesions, which is important for pathologic interpretation of QSM and R2* patterns. A new MS lesion initially presents as nodular-enhancing on T1WI + Gd. This early stage of active lesion development is characterized by breakdown of the $\mathrm{BBB},{ }^{21}$ manifesting as enhancement throughout the lesion on T1WI $+\mathrm{Gd},{ }^{20}$ and myelin damage and uptake by macrophages. The myelin breaking down into debris leads to reduced microstructural heterogeneity, manifesting as $\mathrm{R} 2{ }^{*}$ hypointensity. At this point, iron does not accumulate in microglia and macrophages, making lesions isointense on QSM. Edema that is present in acute lesions as detected on T2WI may dilute susceptibility contents, decreasing both R2* and QSM. However, our data of QSM isointensity suggest that edema only marginally affects QSM.

As the BBB is reconstituted starting in the center of the lesion, within a timeframe of 1 week to several months (average 3 weeks), ${ }^{22,23}$ the enhancement pattern changes from nodular- to shell-enhancing on T1WI $+\mathrm{Gd}^{20,23,24}$ Myelin debris in the lesion's center is also being further degraded within macrophages, some of which are moving out of the lesion into the peripheral circulation $^{2,25,26}$ (see myelin content difference between the 2 le- sions in Fig 1 in Mehta et $\mathrm{al}^{27}$ ). This further reduces microstructural heterogeneity and manifests as reduction in R2*. Moreover, loss of diamagnetic lipids increases susceptibility as measured on QSM. Therefore, R2* decrease and QSM increase reflect degradation and removal of myelin debris.

As MS lesions mature into chronic lesions with a closed BBB, iron accumulates predominantly in microglia at the lesion rim, which has been suggested to promote proinflammatory polarization in these cells. ${ }^{27,28}$ In contrast to demyelination that causes QSM increase and R2* decrease, iron accumulation increases both QSM and $\mathrm{R} 2{ }^{*}$. Therefore, simultaneous increase in both QSM and R2* when lesions change from enhancing to nonenhancing may be interpreted as iron accumulation in lesions. There may be slow removal of residual lip degradation products at the same time, but that would only marginally increase QSM and decrease R2*.

It should be noted that BBB recovers at different rates, ${ }^{21,29}$ which may explain the few outliers that we observed. The QSM hyperintensity in 3 nodular-enhancing lesions may be caused by delayed repair of the BBB or accelerated degradation of myelin. Likewise, the 3 shell-enhancing lesions that are QSM isointense may exhibit fast repair of BBB leakage that leaves no time for susceptibility contents (ie, myelin lipids) to change. Compared with nodular-enhancing lesions, shell-enhancing lesions were captured less frequently in this study and may have more complex structures caused by dynamic pathology. ${ }^{30}$

MS lesion appearances on QSM and $\mathrm{R}^{*}$ captured at one time point have been reported as heterogeneous or diverse. ${ }^{31}$ This diversity in susceptibility and $\mathrm{R} 2{ }^{*}$ values may be caused by the capture of lesions in different stages of development. The dynamic susceptibility change in MS lesion, suggested first by phase imaging $^{8}$ and cross-section QSM, ${ }^{7}$ has recently been confirmed in a longitudinal QSM study. ${ }^{32}$ Our study provides further evidence of dynamic changes in lesion susceptibility and $\mathrm{R} 2{ }^{*}$. Here, we attempt to explore the relationship between lesion susceptibility and $\mathrm{R} 2{ }^{\star}$ signal with the underlying pathophysiologic changes that occur over time in MS lesions. ${ }^{2}$ This provides a biophysically meaningful way to understand lesion diversity, which may be translated into improved patient management.

For example, the data in Fig 6 suggest that 1) T2WI lesions with relative susceptibility value near zero may be nodular-enhancing, opening another venue for the current exploration of identifying enhancing lesions without Gd injection ${ }^{33-35}$ and 2) simultaneous QSM and R2* increases indicate iron accumulation 
in MS lesions, offering an in vivo tool to study iron-related inflammation behind a sealed BBB that cannot be demonstrated with conventional imaging.

There were several limitations in our study. First, this study was not based on longitudinal evaluation of MS lesions but on cross-sectional data. Second, the number of shell-enhancing lesions was low compared with the other types of lesions. Thus, our cross-sectional results warrant future longitudinal studies that may address both limitations.

\section{CONCLUSIONS}

Early lesions that are nodular-enhancing on T1WI + Gd show decrease in R2* but no change in QSM, reflecting early breakdown of myelin. As lesions evolve toward shell-enhancing, susceptibility increases and $\mathrm{R} 2 *$ further decreases with progressive degradation and removal of myelin debris. Finally, as lesions become chronic, iron accumulation is demonstrated as both QSM and R2* increase. Thus, combining QSM and R2* can help identify changes in myelin and iron contents as white matter MS lesions develop.

Disclosures: Susan Gauthier-UNRELATED: Consultancy: Genzyme, Biogen, Comments: Participated in advisory board meeting; Grants/Grants Pending: Genzyme, Biogen, Novartis, Questcor, EMD Serono. Weiwei Chen—RELATED: Grant: National Natural Science Foundation of China (81401390).* Yi Wang-RELATED: Grant: National Institutes of Health (R01EB013443, R01NS090464)*; UNRELATED: Grants/ Grants Pending: National Institutes of Health*; Patents (planned, pending or issued): Cornell University, ${ }^{*}$ Comments: One of the inventors named on QSM patent; OTHER RELATIONSHIPS: Ownership in Medimagemetric LLC, which is working with Cornell University on QSM commercialization. David Pitt-UNRELATED: Consultancy: Biogen Idec; Grants/Grants Pending: Biogen Idec, Novartis; Payment for Lectures (including service on speakers bureaus): Biogen Idec. *Money paid to the institution.

\section{REFERENCES}

1. Lassmann H. Review: the architecture of inflammatory demyelinating lesions: implications for studies on pathogenesis. Neuropathol Appl Neurobiol 2011;37:698-710 CrossRef Medline

2. Kutzelnigg A, Lassmann H. Pathology of multiple sclerosis and related inflammatory demyelinating diseases. Handb Clin Neurol 2014;122:15-58 CrossRef Medline

3. Filippi M, Rocca MA, Barkhof F, et al. Association between pathological and MRI findings in multiple sclerosis. Lancet Neurol 2012; 11:349-60 CrossRef Medline

4. Haacke EM, Makki M, Ge Y, et al. Characterizing iron deposition in multiple sclerosis lesions using susceptibility weighted imaging. $J$ Magn Reson Imaging 2009;29:537-44 CrossRef Medline

5. Hagemeier J, Heininen-Brown M, Poloni GU, et al. Iron deposition in multiple sclerosis lesions measured by susceptibility-weighted imaging filtered phase: a case control study. J Magn Reson Imaging 2012;36:73-83 CrossRef Medline

6. Paling D, Tozer D, Wheeler-Kingshott C, et al. Reduced R2' in multiple sclerosis normal appearing white matter and lesions may reflect decreased myelin and iron content. J Neurol Neurosurg Psychiatry 2012;83:785-92 CrossRef Medline

7. Chen W, Gauthier SA, Gupta A, et al. Quantitative susceptibility mapping of multiple sclerosis lesions at various ages. Radiology 2014;271:183-92 CrossRef Medline

8. Wiggermann V, Hernández Torres E, Vavasour IM, et al. Magnetic resonance frequency shifts during acute MS lesion formation. $\mathrm{Neu}$ rology 2013;81:211-18 CrossRef Medline

9. Bagnato F, Hametner S, Yao B, et al. Tracking iron in multiple sclerosis: a combined imaging and histopathological study at 7 Tesla. Brain 2011;134:3602-15 CrossRef Medline

10. Hammond KE, Metcalf M, Carvajal L, et al. Quantitative in vivo magnetic resonance imaging of multiple sclerosis at 7 Tesla with sensitivity to iron. Ann Neurol 2008;64:707-13 CrossRef Medline

11. Ropele S, de Graaf W, Khalil M, et al. MRI assessment of iron deposition in multiple sclerosis. J Magn Reson Imaging 2011;34:13-21 CrossRef Medline

12. Wang Y, Liu T. Quantitative susceptibility mapping (QSM): decoding MRI data for a tissue magnetic biomarker. Magn Reson Med 2015;73:82-101 CrossRef Medline

13. de Rochefort L, Liu T, Kressler B, et al. Quantitative susceptibility map reconstruction from $M R$ phase data using Bayesian regularization: validation and application to brain imaging. Magn Reson Med 2010;63:194-206 CrossRef Medline

14. Wang Y. Principles of Magnetic Resonance Imaging: Physics Concepts, Pulse Sequences \& Biomedical Applications. CreatSpace Independent Publishing Platform; 2012

15. Yablonskiy DA, Luo J, Sukstanskii AL, et al. Biophysical mechanisms of MRI signal frequency contrast in multiple sclerosis. Proceedings of the National Academy of Sciences of the United States of America 2012;109:14212-17 CrossRef Medline

16. Schweser F, Deistung A, Lehr BW, et al. Quantitative imaging of intrinsic magnetic tissue properties using MRI signal phase: an approach to in vivo brain iron metabolism? Neuroimage 2011;54: 2789-807 CrossRef Medline

17. Liu J, Liu T, de Rochefort L, et al. Morphology enabled dipole inversion for quantitative susceptibility mapping using structural consistency between the magnitude image and the susceptibility map. Neuroimage 2012;59:2560-68 CrossRef Medline

18. Baudrexel S, Volz S, Preibisch C, et al. Rapid single-scan T2*-mapping using exponential excitation pulses and image-based correction for linear background gradients. Magn Reson Med 2009;62: 263-68 CrossRef Medline

19. Jenkinson M, Bannister P, Brady M, et al. Improved optimization for the robust and accurate linear registration and motion correction of brain images. Neuroimage 2002;17:825-41 CrossRef Medline

20. Gaitan MI, Shea CD, Evangelou IE, et al. Evolution of the bloodbrain barrier in newly forming multiple sclerosis lesions. Ann Neurol 2011;70:22-29 CrossRef Medline

21. Schoderboeck L, Adzemovic M, Nicolussi EM, et al. The "window of susceptibility" for inflammation in the immature central nervous system is characterized by a leaky blood-brain barrier and the local expression of inflammatory chemokines. Neurobiol Dis 2009;35: 368-75 CrossRef Medline

22. He J, Grossman RI, Ge Y, et al. Enhancing patterns in multiple sclerosis: evolution and persistence. AJNR Am J Neuroradiol 2001; 22:664-69 Medline

23. Cotton F, Weiner HL, Jolesz FA, et al. MRI contrast uptake in new lesions in relapsing-remitting MS followed at weekly intervals. Neurology 2003;60:640-46 CrossRef Medline

24. Guttmann CR, Ahn SS, Hsu L, et al. The evolution of multiple sclerosis lesions on serial MR. AJNR Am J Neuroradiol 1995;16:1481-91 Medline

25. Lee SC, Moore GR, Golenwsky G, et al. Multiple sclerosis: a role for astroglia in active demyelination suggested by class II MHC expression and ultrastructural study. J Neuropathol Exp Neurol 1990;49: 122-36 CrossRef Medline

26. Bruck W, Porada P, Poser S, et al. Monocyte/macrophage differentiation in early multiple sclerosis lesions. Ann Neurol 1995;38: 788-96 CrossRef Medline

27. Mehta V, Pei W, Yang G, et al. Iron is a sensitive biomarker for inflammation in multiple sclerosis lesions. PloS One 2013;8:e57573 CrossRef Medline

28. Hametner S, Wimmer I, Haider L, et al. Iron and neurodegeneration in the multiple sclerosis brain. Ann Neurol 2013;74:848-61 CrossRef Medline

29. Lassmann H. A dynamic view of the blood-brain barrier in active multiple sclerosis lesions. Ann Neurol 2011;70:1-2 CrossRef Medline 30. Henderson AP, Barnett MH, Parratt JD, et al. Multiple sclerosis: 
distribution of inflammatory cells in newly forming lesions. Ann Neurol 2009;66:739-53 CrossRef Medline

31. Li X, Harrison DM, Liu H, et al. Magnetic susceptibility contrast variations in multiple sclerosis lesions. J Magn Reson Imaging 2016; 43:463-73 CrossRef Medline

32. Zhang Y, Gauthier SA, Gupta A, et al. Longitudinal change in magnetic susceptibility of new enhanced multiple sclerosis (MS) lesions measured on serial quantitative susceptibility mapping (QSM). J Magn Reson Imaging 2016 Jan 22. [Epub ahead of print] CrossRef Medline
33. Shinohara RT, Goldsmith J, Mateen FJ, et al. Predicting breakdown of the blood-brain barrier in multiple sclerosis without contrast agents. AJNR Am J Neuroradiol 2012;33:1586-90 CrossRef Medline

34. Treabă CA, Bălaşa R, Podeanu DM, et al. Cerebral lesions of multiple sclerosis: is gadolinium always irreplaceable in assessing lesion activity? Diagn Interv Radiol 2014;20:178-84 CrossRef Medline

35. Blystad I, Håkansson I, Tisell A, et al. Quantitative MRI for analysis of active multiple sclerosis lesions without gadolinium-based contrast agent. AJNR Am J Neuroradiol 2016;37:94-100 CrossRef Medline 